\title{
Artigo \\ Dos mercados informais às políticas não hegemônicas de valor: olhares cruzados entre Porto Alegre e Buenos Aires na produção de objetos e sujeitos camelôs
}

\author{
Moisés Kopper ${ }^{1}$ \\ Universidade Federal do Rio Grande do Sul
}

RESUMO: A antropologia dos mercados informais sempre enfrentou com alguma dificuldade o problema básico de propor definições acerca do que seja o informal. Economistas e sociólogos propuseram conceituações por demais generalizantes, atrelando-as à economia formal; antropólogos esbarram em concepções excessivamente particularizantes, muitas vezes negando a capacidade heurística da noção. Esse artigo sugere uma terceira via para o problema, explorando as políticas econômicas de produção do valor de sujeitos, objetos e lugares, uns em relação de mútua definição com os outros. O enfoque recai sobre as disputas de sentido a partir de onde certos discursos sobre a informalidade - imaginados, móveis e incompletos - são materializados e performatizados. Etnograficamente, parte, de um lado, da transição do mercado de rua para um shopping popular, em Porto Alegre/RS; de outro, dos debates públicos entre jornalistas, empresários e mercadores acerca da expansão da feira informal "La Salada", considerada a maior do mundo, em Buenos Aires.

PALAVRAS-CHAVE: Informalidade, formalização, valor, etnografia, camelódromo, La Salada. 


\section{Introdução}

Desde os tempos mais remotos, os mercadores de rua existem em toda parte, e são um componente essencial da paisagem e arquitetura das grandes cidades. Com eles, e através de seus rastros, estabeleceram-se circuitos e entrepostos comerciais de diferentes magnitudes, escalas e alcances, capazes de conectar diversas partes do mundo, através de nódulos que são um mundo à parte (Wallerstein, 1974; Wolf, 1982; Hannerz, 2011). Juntos, mercadores e mercados, sujeitos e objetos, conformam mutuamente redes articuladas de nós e fluxos de informação, pessoas, mercadorias e capital - aquilo que Gustavo Lins Ribeiro (2010) denominou de sistema mundial não hegemônico, com isso referindo-se às composições de “de várias unidades localizadas em diferentes glocais conectados por agentes operando na globalização popular” (2010: 28), por sua vez em tensão com o sistema mundial hegemônico, baseado na lógica institucional e operativa dos detentores de poder tanto no que diz respeito ao Estado como ao capital privado. Sua intenção consiste, grosso modo, em jogar luz sobre as rede de produtores, vendedores e consumidores que usualmente não são considerados nas análises sobre globalização e, portanto, complexificar o debate em torno das categorias legítimas a partir das quais são definidas noções simultaneamente tão amplas e restritas, como "mercado informal" e comerciantes de rua ${ }^{2}$.

Tomando por base o esforço interpretativo de Ribeiro (2010), e baseando-me em uma miríade de trabalhos mais e menos etnográficos e teóricos, desenvolvidos em diferentes momentos no âmbito da cultura material, dos estudos de consumo, e de mercados alternativos, esse artigo pretende sugerir que mesmo uma interpretação "não hegemônica" de circuitos de comércio informal esbarra no problemático enigma conceitual de sua definição. Exceto por uma tentativa de amplificar a diversidade interna à categoria, esta permanece numa relação de dependência normativa com o seu par antagônico - qual seja, a noção deveras ampla e englobante de "economia formal" - e qualquer conceituação daí resultante torna-se epistemologicamente tributária de uma disputa semântica anterior, em que a própria definição do objeto é parte de uma política de imaginação e localização de certos fenômenos no interior de campos econômicos tomados como já previamente estabelecidos.

Sugiro, de modo alternativo, que outro modo de imaginar tais fenômenos está em decompor analiticamente o quadro mais amplo em que concorrem políticas de formação de valor dos sujeitos, objetos e lugares, uns em relação de mútua complementaridade com os outros. Isso implica em que, ao invés de direcionarmos nosso olhar sobre definições 
prontas e acabadas do que sejam comerciantes informais, ou mercados não hegemônicos, focalizemos nossa atenção sobre as políticas econômicas de valoração (isto é, de produção do valor) necessariamente incompletas e inacabadas, pelas quais certos sujeitos tornam-se definíveis em relação a certos objetos que colocam em circulação, nas interfaces com certos espaços heterópicos que lhes servem de contexto e suporte - produzindo, assim, cenários econômicos imaginados e móveis, ainda que de um tipo particular, apenas parcial e imperfeitamente imputável de "informal" e contra-hegemônico.

$\mathrm{Na}$ origem desse empreendimento compreensivo encontra-se um exaustivo e sistemático trabalho de campo, realizado nas cidades de Buenos Aires - entre agosto e novembro de 2011, como parte de um estágio de intercâmbio Capes-CAPG, na Universidad Nacional de San Martín - e Porto Alegre - entre 2008 e 2011, período em que concluí a graduação em Ciências Sociais e o mestrado em Antropologia Social no Programa de PósGraduação da Universidade Federal do Rio Grande do Sul. Na cidade de Porto Alegre, ocupei-me com o acompanhamento etnográfico de um processo de reassentamento que envolveu o deslocamento de aproximadamente 800 bancas de camelôs instaladas nas ruas do centro histórico para um empreendimento público-privado, por alguns chamado de shopping popular e por outros, simplesmente, de camelódromo. Em Buenos Aires, interessei-me pelos debates públicos, via de regra dramatizados nas grandes mídias locais, que emergiram às vésperas das eleições nacionais de 2011, protagonizados entre representantes de uma das maiores feiras de comércio informal do mundo - La Salada -e figuras públicas, políticos, intelectuais e jornalistas. Além disso, segui os rastros de sua expansão pelos centros urbanos da capital argentina, visitando e acompanhando os controversos debates em torno da instalação das assim chamadas "Saladitas" - derivações menores dessa feira que surgiram a partir dos anos 2000.

Esse artigo estrutura-se em duas metades etnográficas e uma discussão teórica que lhe serve de base. Na primeira parte, apresento os contextos empíricos a partir dos quais foram trabalhados os principais argumentos esboçados, concentrando-me na problematização do papel de agentes-chave dos processos de formalização econômica, no contexto do camelódromo de Porto Alegre, e de expansão das feiras informais, no caso de La Salada e suas derivações, em Buenos Aires. Na segunda parte, apresento uma discussão teórica, acompanhada de reflexões sobre a etnografia, na tentativa de estabelecer nexos significativos nas relações entre sujeitos, objetos e lugares para a arquitetura das políticas de valoração do caráter informal desses processos. Encerro com uma discussão a respeito do 
caráter heterópico (Foucault, 1984) desses lugares enquanto nódulos particulares de um sistema mais amplo.

\section{O camelódromo de Porto Alegre e as dinâmicas de apropriação do tempo e do espaço}

Em 2005, após dezesseis anos na prefeitura de Porto Alegre, o PT cedeu o comando da capital gaúcha para um bloco de partidos liderado por José Fogaça, na época do Partido Popular Socialista (PPS). Uma das primeiras iniciativas da nova administração constituiu-se na proposição de um projeto de remoção dos comerciantes ambulantes das principais ruas onde foram concentrados, ao longo dos cerca de cinquenta anos em que diversas políticas públicas trataram de classificá-los, delimitá-los, esquadrinhá-los, cadastrá-los, listá-los e regulamentá-los. Como alternativa para a reacomodação, sugeriu-se a construção de um megaempreendimento de mais de 20 mil metros quadrados, no centro da capital gaúcha, dividido em dois grandes blocos articulados por meio de uma passarela, chamados, respectivamente, de A e $\mathrm{B}$.

Localizado na Praça Ruy Barbosa, sobre dois terminais de ônibus, em pleno "coração" da cidade - a algumas quadras da Prefeitura Municipal, do Mercado Público, e em duas das vias de comércio popular mais frequentadas por compradores de todo o estado -, o camelódromo seria tomado como a marca da nova administração, tendo sido aberto à população em fevereiro de 2009 e, portanto, tendo contribuído para a reeleição do mesmo bloco de partidos ao poder. Ao longo dos mais de três anos durante os quais a obra foi apresentada, discutida e negociada, o projeto sofreu diversas modificações em sua concepção, estrutura, e nos critérios de implementação, acesso e divisão dos boxes, cujas dimensões finais raramente alcançam quatro metros quadrados cada. Até a sua nomenclatura foi alterada em diversas ocasiões, de acordo com o equilíbrio de forças entre o governo municipal e os novos, assim denominados pela lei, comerciantes populares: de camelódromo, para Centro Popular de Compras, para Shopping do Porto e, finalmente, para Pop Center - embora para seus principais usuários ele nunca deixasse de ser conhecido pelo que realmente significava: um camelódromo.

A realocação dos camelôs foi um projeto ousado e inovador por parte dos gestores municipais. Embora não tenha sido o primeiro do gênero no Brasil, envolveu um conjunto extenso de variáveis que precisaram ser equacionadas com habilidade, sendo a principal 
delas, sem dúvida, o consentimento dos próprios camelôs. O uso da repressão pura e simples se mostrou, ao longo dos anos, uma estratégia economicamente inócua - pois os camelôs mudam de lugar ou retornam depois de certo tempo - e politicamente desgastante - uma vez que os camelôs se reivindicam como trabalhadores honestos e encontram nisso solidariedade junto ao público mais amplo. A alternativa mais sensata, aquela que permitia ao poder público trabalhar no registro da "negociação" e do "diálogo", ao mesmo tempo em que lavava as mãos quanto ao ônus financeiro decorrente da construção do prédio, foi encontrada na celebração, em 2006, de um contrato de Parceria Público-Privada (PPP), a primeira de Porto Alegre e uma das pioneiras do Brasil. Assim, a PPP possibilitou a introdução de um terceiro agente nas negociações entre o governo e os comerciantes de rua.

Tal contrato, celebrado com a empresa Verdicon S.A., pressupunha a concessão, através de licitação, de uma área nobre no coração do centro para a construção de um espaço capaz de abrigar, contiguamente, 800 camelôs previamente cadastrados junto à Secretaria Municipal de Produção, Indústria e Comércio (SMIC). A empresa assumiria o ônus da construção do edifício e, como contrapartida, lhe seria concedido o direito de exploração do empreendimento através da cobrança de alugueis semanais dos novos inquilinos. Com isso, o poder público respondia, simultaneamente, às expectativas dos setores da economia formal, que exigiam a reurbanização e higienização do centro de Porto Alegre $^{3}$, bem como aos anseios da opinião pública, que via com certa resistência o investimento de recursos públicos vultosos para tratar de um setor malquisto da população e que, ademais, nem bem se compunha de residentes da capital ${ }^{4}$.

O camelódromo inseria-se, assim, como parte de um processo mais amplo de reconfiguração dos espaços e aparelhos coletivos dos centros das grandes metrópoles brasileiras, simultaneamente removendo sujeitos indesejáveis, onerosos e perigosos à economia formal, oxigenando-a, e submetendo-os, por meio de uma série de políticas de formalização subsequentes à ocupação do prédio, à conversão em comerciantes populares ou ainda microempresários. Isso porque a mesma empresa que havia vencido o processo de licitação para a exploração comercial do espaço recebera, igualmente, a difícil tarefa de, doravante, tornar viável o empreendimento econômico - seja porque o poder público se havia retirado da mesa de negociações, seja porque, em última instância, eram os seus investimentos que estavam em risco.

Mais que um jogo de palavras, o conjunto de ações de marketing empreendidos pela empresa administradora visava à fabricação de uma nova subjetividade comercial, por 
sua vez adequada à proposição do camelódromo como "shopping popular", vale dizer, como receptáculo de novos fluxos de clientela que tinha interesse nessa modalidade de mercado em reconfiguração. Instigada pelo projeto de PPP proposto pelo poder público municipal, que estipulava um prazo total de 35 anos de exploração do empreendimento através de alugueis cobrados diretamente dos camelôs, além das áreas complementares formadas por salas comerciais, a empresa tratou de apostar as poucas fichas que the restavam num investimento que, dado seu ineditismo, poderia ser considerado, em termos mercadológicos, como de alto risco.

Não bastava apenas fazer com que os camelôs vendessem o suficiente para pagar os alugueis. Tratava-se, mais fundamentalmente, de "elevar o nível" do camelódromo ao estatuto de "shopping popular", destinado ao consumo de uma "nova classe média", que deveria voltar a ocupar o centro após uma série de políticas de revitalização que incluíam a própria remoção dos camelôs das ruas, e com isso também formar novos padrões de vendedores. $\mathrm{Na}$ prática, a empresa aproveitou a crise de inadimplência dos alugueis, gerada por um grupo crescente de comerciantes queixosos e menos capitalizados. Isso lhe permitiu empreender um arrojado projeto de ressocialização econômica desses trabalhadores que, mais do que salvar a empresa da bancarrota a que tinha chegado pela inadimplência, tinha o objetivo de torná-los bons pagadores, para que não oferecessem resistência às campanhas de marketing que passariam a ser conduzidas pela empresa para recuperar a imagem política e socialmente desgastada que havia sido deixada pelo ideia do camelódromo como um amontoado de ambulantes e bugigangas sem valor.

\section{De La Salada às Saladitas: expansão das feiras informais na Argentina}

Em agosto de 2011, quando iniciei o estágio de mestrado na Universidad Nacional de San Martín, estava convicto de que a grande feira informal "La Salada" poderia estabelecer um ponto de inflexão estratégico em relação às dinâmicas de formalização observadas em Porto Alegre. Situada às margens de uma vala de esgoto a céu aberto do rio Riachuelo, que separa as províncias de Buenos Aires e Lomas de Zamora, La Salada é um dos mais rentáveis negócios imobiliários da Argentina. Funciona duas vezes por semana, comercializando, em sua maioria, roupas e calçados falsificados, em horários pouco convencionais, e movimenta, anualmente, em média, 2,7 bilhões de dólares (cf. Girón, 2011; Hacher, 2011). A feira inicia suas atividades à meia-noite e encerra às seis horas da 
manhã, em dois dias específicos da semana, colocando em marcha cerca de 200 mil pessoas por madrugada, oriundas de diferentes províncias da Argentina.

De acordo com o sítio web oficial da feira, La Salada iniciou suas atividades em 1991, "con un puñado de ciudadanos de nacionalidad boliviana que se instalaron a vender ropas importadas y comida en terrenos abandonados en la localidad lomense de Ingeniero Budge, que en tiempos de Perón estaban acondicionados como balnearios" ${ }^{25}$. Em pouco tempo, com a rentabilidade do negócio, e o progressivo aumento do número de famílias a ocupar a região, formou-se a feira Urkupiña S.A., que posteriormente, com o ingresso constante de novos comerciantes, agregaria outras duas, Cooperativa Ocean e Punta Mogotes S.A.. Com a crise econômica de princípios de 2000, a venda de eletrodomésticos e importados foi substituída por roupas, calçados e mídias (CDs e DVDs), que se tornaram os grandes artefatos de comercialização em torno dos quais a grande feira La Salada - que leva esse nome pela proximidade do terreno com a lagoa Salada - se consolidou e amplificou. $\mathrm{O}$ aumento exponencial na taxa de desemprego fez com que muitos produtores, inicialmente do setor formal, migrassem para a informalidade e passassem a reproduzir as mesmas técnicas na produção de mercadorias truchas - isto é, calçados e confecções falsificados, que carregam os nomes e atributos de grandes marcas, embora sejam produzidos para além de seus circuitos formais.

Fenômeno ainda mais recente, La Salada proliferou-se e capilarizou-se através de pequenas feiras e shoppings de comércio informal, instaladas em diferentes partes do perímetro urbano da cidade de Buenos Aires. As assim chamadas Saladitas comercializariam todo tipo de confecções e artigos produzidos e vendidos na grande feira à qual devem seu nome, embora a um preço ligeiramente superior em função de incrementos nos custos de logística e de segurança. Mais importante do que a própria constituição desses mercados informais pulverizados, é o pressuposto tácito em torno da configuração de circuitos informalizados que expandem também certo modo de fazer, gestar e organizar o funcionamento de mercados simultaneamente acéfalos e encadeados, constituídos em torno de movimentos cíclicos, que emergem de estruturas englobantes mais amplas, e assim sucessivamente, numa espiral indefinida.

Estava claro, portanto, que La Salada se configurava como o centro de uma rede de feiras regionais - aquilo que D’Angiolillo (s/d) chamou de “centralidade periférica" - e o nó de uma rede global de comércio informal, sendo o estudo de suas ramificações urbanas tão importante quanto sua arquitetura interna. O termo "Saladitas", aliás, estava longe de ser gratuito; apesar da referência explícita que essas feiras urbanas mantinham, em termos 
de artefatos e dinâmicas de venda, com La Salada, era nítido que se tratava de um projeto de classificação que tinha sua origem nas agências midiáticas e em instituições econômicas oficiais - como é o caso da Câmara Argentina de Comércio e da Confederación Argentina de la Mediana Empresa (CAME) -, encarregadas de noticiar, prevenir e alertar para os perigos que representavam para o equilíbrio fiscal do país ${ }^{6}$.

A grande narrativa midiática - passível em si mesma de ser tomada como porta-voz das grandes instituições comerciais de Buenos Aires, de onde toma boa parte dos dados e números apresentados - fornece a cartografia moral dos espaços "tomados" pelas Saladitas. Como argumentarei mais adiante, o desconforto que os redatores supõem causar no público leitor joga com uma paradoxal aproximação moral entre artefatos ilícitos e sujeitos "de bem", mediada por um sobreposicionamento espacial entre ambos, que consiste na chegada reconfigurada da Salada - e de tudo que ela representa - à cidade. Por hora, contudo, é suficiente considerar tais narrativas midiáticas como modelos em torno dos quais é possível erigir pontos de tensão a partir das observações etnográficas decorrentes da pesquisa de campo antropológica.

\section{O cotidiano no camelódromo: os agentes e suas práticas}

Não seria possível compreender em profundidade os caminhos delineados pelo processo de transição do mercado de rua para um shopping popular, em Porto Alegre, sem observar os conflitos e tensões de longa data estabelecidos entre os diversos grupos de camelôs das ruas do centro da cidade. Desde as medidas paliativas tentadas ao longo dos anos 1990 para o remanejo, nas ruas, dos camelôs cadastrados pela SMIC, até às controversas políticas de distribuição dos boxes do novo empreendimento, em 2008, tudo se passou como se duas grandes facções tivessem se estabelecido entre os comerciantes de rua. De um lado, havia a Associação Feira da Rua da Praia (Asferap), que surgiu no final dos anos 1990, devido a irregularidades na ocupação da Rua da Praia, e que desde sempre procurou negociar a sua permanência nas ruas com o poder público. De outro, estavam os grupos de camelôs estabelecidos há mais tempo no entorno da Praça XV. Na verdade, era ali que se concentrava a maior parte dos ambulantes do centro, ao menos aqueles que foram oficialmente cadastrados para exercerem suas atividades em praça pública. Entre ambas as facções não havia diferenças sociais e econômicas significativas; na verdade, o termo faç̧ão, 
de uso específico na antropologia da política, não é gratuito, na medida em que era no campo da política que os conflitos e as dissemelhanças emergiam (Kopper, 2012: 34-110).

À medida que o empreendimento tomava forma, Alfonso Limberger, principal representante entre os camelôs cadastrados do entorno da Praça XV, passou a enxergá-lo como uma grande oportunidade de propulsionar as vendas, suas e de seu grupo. Para tanto, bastava adequar a sabedoria comercial adquirida durante anos de trabalho nas ruas, e equacioná-la para que seus colegas pudessem se apropriar dela como medida do bom comerciante, do camelô ajustado aos novos tempos e recursos. A esse movimento, Alfonso chamou de profissionalização da figura o camelô. Mais que uma reinvenção, tratava-se de inventariar as técnicas de comércio já existentes na rua, agregando-as e ajustando-as à nova ordem entre sujeito, lugar e coisa, fruto dos fluxos de pessoas, capital e clientes do camelódromo. Essa nova gramática das relações sociais estava fundamentada na perda da autonomia do sujeito camelô diante de seu produto e de seu cliente: um novo perfil de comerciante, arrojado, atento às tendências da moda e do consumo atuais, preocupado com as oportunidades do momento e em estar à frente de seus colegas, passou a estabelecer novas hierarquias morais entre os sujeitos. Entre aqueles capazes de prever as novas tendências e antecipar os produtos, aumentando cada vez mais o dinheiro em circulação e a frequência de viagens ao Paraguai, Uruguai e São Paulo, e aqueles que, sem essa sensibilidade, deveriam se contentar com lucros menores e sonhos de expansão mais modestos.

Nesse processo, a agência mediadora de Alfonso consistia, entre outras coisas, em instigar as relações de concorrência e de inveja, ao menos da "boa inveja", aquela que permitia ao comerciante estar atento às estratégias de seus vizinhos de banca, que permitia, enfim, copiar suas táticas de comércio. Ou até, por que não, comprar o ponto do colega, sublocá-lo ou propor parcerias, caso ele não suportasse o ritmo do jogo e desistisse do negócio. Ofertas cada vez mais generosas se acumulavam pelos corredores do camelódromo, e negociações de pontos podiam passar de 50 mil reais nesse pequeno mercado imobiliário local. Assim, pequenos atacados e núcleos de comércio acabavam por se formar, sobretudo no bloco A, onde Alfonso conseguia prospectar a maior parte dos camelôs, com bancas acopladas umas às outras, auxiliares e funcionários de venda, música ambiente, máquinas de cartão de crédito, internet, telefones, mostradores, manequins, e por aí afora.

Alfonso também desenvolveu um acurado senso estatístico, que lhe permitiu prever o que ocorreria com seus colegas e potenciais concorrentes: cerca de $25 \%$ cairia logo de 
início, outros tantos desistiriam nas primeiras semanas. E, à medida que as desistências se assomavam, como resultado do fracasso econômico individual mas também do desgaste político das mobilizações empreendidas por seu adversário, mais e mais pessoas lhe procuravam como representante legítimo do camelódromo. Além de intermediar as expectativas dos camelôs com as da empresa e do governo, Alfonso lhes ensinava como manter e ampliar a banca. Ensinava-os a fazer uso da retórica do comerciante popular, o que significava passar a encarar o próprio negócio como um empreendimento pessoal, e o pagamento do aluguel como o resultado positivo da competência de vendas adquirida pelo empenho individual. Com o crescimento das bancas, e a aceitação e incorporação dessa pedagogia de vendas, Alfonso passou a ensinar como administrar o dinheiro, e como lidar com os imprevistos financeiros e a inveja de colegas, vizinhos e parentes. O sucesso do empreendimento de cada novo comerciante popular passou a ser também o sucesso de Alfonso, como narrador e mediador legítimo dessas trajetórias de transição e ascensão social.

Não se pode negar que a filosofia pragmática de Alfonso tenha tido alcance significativo, e havia mesmo quem acreditasse ser sua pedagogia a única possibilidade de adaptação aos novos espaços e tempos sugeridos pelo camelódromo. Outros, entretanto, seguiram, desde o princípio, caminhos alternativos: tratava-se dos membros da Associação Feira da Rua da Praia - Asferap. A expansão desse grupo foi relativamente rápida e, apesar de pouco capitalizados, passaram a reunir parte significativa dos ambulantes que diariamente vinham da região metropolitana de Porto Alegre. Eram liderados por Juliano Fripp, uma figura que, entre outras coisas, militava em partidos de extrema esquerda, tendo se candidatado algumas vezes a cargos políticos. A permanência no entorno da Rua da Praia, onde se instalaram desde bem antes de sua organização formal, nunca foi expressamente regulamentada pelo poder público, razão pela qual tiveram de empreender diversas disputas - junto à prefeitura, mas também pelas entranhas do Orçamento Participativo, que lhes garantia a cidadania política necessária ao reconhecimento como sujeitos de direitos - para assegurar os horários de trabalho em períodos curtos e específicos do dia.

Com a divisão dos boxes, meses antes da abertura, esse grupo foi destinado para o bloco B do empreendimento - de menor fluxo de vendas e com bancas de menor tamanho. Juliano atribuiu o revés a derrotas políticas, e optou pelo enfrentamento organizando uma mobilização política por dentro do Estado -, para que o empreendimento produzisse sustentabilidade social e não extinguisse, como se previa, os 
"camelôs" como categoria de trabalhadores. Com a abertura do camelódromo, Juliano seria eleito para a primeira gestão do Comitê Gestor $^{7}$, iniciaria um novo ciclo de mobilizações políticas, no acionamento de instituições cardinais da democracia, como a Câmara de Vereadores, a Prefeitura Municipal e a mídia local. Tratava-se, doravante, de tentar impedir que seus colegas, então já com dificuldades de adaptação e de pagamento dos novos encargos, fossem despejados pela empresa encarregada da administração do prédio - as reivindicações incluíam a proposição de períodos de carência no valor dos alugueis cobrados, além de um zoneamento consoante os fluxos diferenciados de clientes.

Passados catorze meses, contudo, uma ação de despejo perpetrada pela SMIC, com apoio da Polícia Militar, daria cabo ao sonho do camelódromo de cerca de uma dezena de comerciantes, entre os quais o próprio Juliano. Muitos deles não haviam sequer pago uma semana de aluguel, motivados por um projeto político de contestação às condições de comércio instituídas - que obrigavam, como medida de sobrevivência econômica, a sublocações, parcerias informais, mudanças de mercadorias, de rotas de obtenção e de técnicas de comercialização, para não falar de desistências, falências e conflitos de sociabilidade entre camelôs, clientes e representantes da administração e do poder público (Kopper, 2011). Uma tensão mal resolvida se estabelecia, assim, entre, de um lado, os resquícios de uma expertise aprendida na circulação pelos espaços públicos e, de outro, do que poderíamos chamar de uma pedagogia cotidiana da formalização - em que um projeto coletivo e político de transição era substituído, cotidiana e paulatinamente, pelas táticas inventivas (De Certeau, 1994) e individuais de sobrevivência comercial.

\section{Jorge Castillo e os sentidos da informalidade em "La Salada"}

A pesquisa que conduzi na Argentina apontou, como vimos, para uma proliferação das feiras e mercados informais, sem regulamentação direta estipulada pelo Estado, que se iniciou ainda na década de 1990. Tais organizações são, por sua vez, decorrências diretas da crise de 2001, na medida em que sua instalação, além de contribuir para a fixação de ambulantes, lhes garantia a possibilidade de sobrevivência comercial e econômica, através da criação de associações e organizações civis, dotadas de regulamentos próprios e de um maior poder de negociação para a defesa do espaço de trabalho frente às autoridades públicas e aos vizinhos, que se opõem à sua presença (Beccaria, 2000; 2001; Solano, 2004). 
Por conseguinte, é a expansão das feiras informais, de caráter privado, mais que a própria feira que as originou, em Lomas de Zamora, que suscita a questão do papel regulatório do Estado vis-à-vis à constituição da informalidade enquanto fenômeno econômico, social e político. A esse respeito, os frequentes debates públicos, catalisados pelo andamento das campanhas eleitorais para a presidência da república, entre setembro e outubro de 2011, dão o tom da dramatização do pertencimento nacional a partir de uma imagética do campo econômico.

Grande parte dessas disputas concentravam-se em torno de inquisições jocosas e irônicas de economistas, jornalistas e representantes do comércio formal a Jorge Castillo, principal e talvez único representante público de La Salada. Como salienta em uma das várias entrevistas que concedeu à imprensa, ele iniciou suas atividades econômicas como sapateiro em uma fábrica, até que conseguiu adquirir as primeiras máquinas e começar um negócio próprio. Castillo não é particularmente letrado, não dispondo de outros capitais intelectuais que não o curso técnico de modelista e desenhador de calçados, que lhe permitiu ingressar no mercado de trabalho. Não obstante, é no saber pragmático associado ao ofício, e mais bem na incorporação de uma certa vocação ao trabalho, que encontramos a chave de sua trajetória.

Em 1999, Castillo fundou a feira de "Punta Mogote", a terceira a se estabelecer no complexo de La Salada, e atualmente aquela que mais atrai clientes. De acordo com Girón (2011: 212), entre 2001 e 2005, a estratégia do empreendedor consistiu em duas grandes políticas: investimento estrutural e exposição midiática. "Fui el primero y el único que se dio cuenta de que había que meter efectivo. Puse cloacas, asfalto, paredes, techos. Abrí pasillos anchos, locales cómodos, estacionamientos. Contraté seguridad policial y privada. Y le mostré a la Argentina que se podía venir sin inconvenientes" (Girón, 2011: 212). Poucas são as fontes bibliográficas e midiáticas que duvidariam da excentricidade e ambiguidade de sua figura para o entendimento de La Salada (ver, por exemplo, Hacher, 2011: 43-62). Com efeito, é possível asseverar que não há quaisquer consensos quanto à compreensão do papel que ocupa no funcionamento da grande feira, se não que se confunde com a própria liminaridade - nas fronteiras do legal/ilegal, lícito/ilícito - que confere à Salada seu caráter particular e especial.

Há algum tempo, Castillo deixou de ser comerciante para assumir, definitivamente, o posto de coordenador de La Salada - concentrando e, finalmente, monopolizando as decisões financeiras e de investimentos que cercam o funcionamento da feira. Além disso, participa de uma sociedade composta de 385 acionistas que repartem cerca de 1300 postos 
de trabalho, alugados a preços que podem variar de 500 a 800 pesos por noite de feira. Cada banca pode, ainda, ser sublocada diversas vezes ao longo da mesma feira, de acordo com a quantidade de mercadorias de que dispõe o vendedor; e, como se tratam, em sua maior parte, segundo o próprio Castillo, de produtores próprios - os cuentapropistas -, esse é, no mais das vezes, o caso. Dada a escassez relativa de pontos de venda, formou-se um verdadeiro mercado imobiliário local, o que significa que a venda permanente de cada metro quadrado chega a valer milhares de dólares, de acordo com a localização e as dimensões do box.

O aparelhamento promovido por Castillo em La Salada - que passou a contar com estruturas mais amplas, proteção contra intempéries naturais, segurança privada, monitoramento, estacionamento, tendas de alimentação, etc. -, ao mesmo tempo em que propulsionou o escopo da feira, ampliando seu público frequentador, também suscitou questionamentos e acusações da parte de seus detratores. Entre junho e outubro de 2011, período marcado pelo tempo da política (Palmeira e Herédia, 1995) que precedeu às eleições presidenciais, uma série de debates acerca de seus efeitos políticos, sociais e econômicos foram protagonizados na grande mídia televisiva argentina, os quais colocaram em jogo diferentes modulações semânticas da categoria "inclusão". Para Castillo, La Salada é a própria encarnação de um projeto de sobrevivência social legitimado na informalidade econômica:

Lo insólito no es La Salada, lo insólito son los precios de Santa Fe. Porque este es el precio real. Y el otro precio es el precio de... de grandes lujos que pagamos los consumidores. Y La Salada ha destruido eso yendo directamente del que produce esto, al que lo necesita, al productor, la clase media baja, que es la que concurre a La Salada. Acá no hay ningún milagro, no hay ningún secreto, es eso. El que produce ganará 3, 4 pesos, ganará 5, le saldrá en final 30 pesos, en Santa Fe está esta prenda... debe valer 250 pesos. ¿Y quién se lleva toda esa plata? La parte del león'.

A essas provocações, setores da economia formal rebateram construindo outras fronteiras em torno da "inclusão" - via pagamento de impostos, por exemplo. Tal é o caso de Victor Hugo Benyakar, presidente da Cámara de Indumentaria de Niños y de Bebés, em embate acalorado com Castillo, argumentando por uma "política de inclusão social" das famílias que atuam na feira, em particular, e no comércio informal, em geral.

Es verdad que es el precio real, puede llegar a ser el precio real, si la prenda no es robada en el asfalto, si no es de contrabando. Pero se olvida las cargas 
sociales, se olvida de todos los impuestos, se olvida de todo, y realmente eso es lo que, de alguna manera, genera una inclusión social en un país. Y eso es lo que de alguna manera pretendemos. Nosotros no queremos que La Salada cierre, nosotros no queremos que la gente quede en la calle... (...) ¿Y qué es inclusión social? Pagando las cargas sociales?.

Castillo, por outro lado, baseia sua argumentação na ideia de que se tratam de famílias autônomas, com pequenos negócios de produção própria, com baixa margem de lucro, e com pagamento de impostos na origem do processo econômico - isto é, na compra dos tecidos e da matéria-prima necessária para a fabricação das confecções. Durante a feira, esses comerciantes esgotariam suas vendas em cerca de uma hora e voltariam a sublocar o espaço para terceiros, de modo que a engrenagem desse mercado seria retroalimentada incessantemente, numa espiral cíclica em que se torna difícil observar seu início e seu fim.

Y, bueno, qué van a decir, la verdad no la van a decir. (...) Yo soy un laburante social. Yo ayudo desde cuando no tenía y ahora que tengo ayudo más. Por día entre 50 y 70 personas me piden trabajo. Parezco San Cayetano. Por eso digo que La Salada dignifica al ser humano. Antes la gente vivía de la bolsita que le daban los políticos hijos de puta de turno. Hoy, toda la gente que trabaja conmigo es de Lomas y al darles trabajo los saqué de la delincuencia y de ser los forros de esos putos. (...) Yo a las seis estoy levantado haciendo mi numerito para ver dónde puedo apretar y dónde no. Laburo las 24 horas. El otro día me llamaron a las cuatro de la mañana porque en la feria nos estaban queriendo robar. Los agarramos y eran seis. Yo soy Dios. Yo soluciono todo ${ }^{10}$.

A aparente audácia de Castillo pode ser interpretada como uma crítica pragmática dos poderes estabelecidos, em particular no que concerne à competência das instituições estatais em executar os papeis que constitucionalmente lhe são dirigidos. Tal projeto pressupõe certo conservadorismo de base, na medida em que não sugere a extinção das forças do Estado, mas a crítica de sua desregulação e o desafio de sua reestruturação, capaz de acomodar um novo projeto de nação argentina. Ao mesmo tempo, Benyakar não oferece soluções verdadeiramente novas para o problema - apelando apenas para o retorno à industrialização como modelo desenvolvimentista nacional.

Yo estoy convencido de qué país quiero. Si quiero un país industrial o quiero un país feriante. Yo lo que quiero es que si hay una feria y si hay un montón de gente atrás se puedan industrializar, se puedan hacer competitivos a nivel mundial, se pueda exportar. (...) Gracias a dios tenemos una presidenta [risos de Castillo] que limita las importaciones y hace fabricar la producción nacional pero no quiere que pasen estas cosas, como sale acá de La Salada. (...) Esto es 
un negocio, ¿esto es un país para hacer un negocio de una persona o para hacer un país industrial? ${ }^{11}$

La Salada segue sendo um negócio em plena expansão. Recentemente, Castillo abriu uma sala comercial em Puerto Madero ${ }^{12}$, alegadamente para trazer comodidade aos clientes que não quiserem se deslocar até La Salada - embora, igualmente, com a nítida intenção de desaforar os grandes executivos e representantes do comércio formal, que desde a revitalização do porto concentram suas atividades econômicas e financeiras naquele lugar. Ao mesmo tempo, há projetos em andamento de instalar novos centros comerciais, nos moldes de La Salada, em outras partes da Argentina - como Córdoba e Mendoza -, e, inclusive, em Miami, nos Estados Unidos, onde se chamaria de La Salada Beach.

\section{Da informalidade às políticas econômicas de valor}

Camelôs, comerciantes de rua, vendedores ambulantes, feirantes, e toda sorte de mercadores não regulamentados diretamente pelo Estado, têm sido usualmente definidos, pela literatura clássica da economia e, em grande parte, das ciências sociais, como o outro lado da economia formal - isto é, como agentes distribuídos em algum ponto ao longo de cadeiras de informalidade (Ribeiro, 2010). Tal classificação não é gratuita, na medida em que está erigida em uma pressuposição anterior acerca do que é e como devem ser as relações entre a economia, a política e o Estado. De igual modo, tal clivagem está de acordo com uma divisão intelectual do trabalho, pela qual caberia às ciências ditas "duras" o esquadrinhamento da "infraestrutura real" por trás, supostamente, da engrenagem pressupostos que, por fim, implicam numa hierarquização moral e científica dos campos disciplinares, homóloga à existente na relação entre formalidade e informalidade.

Para além do fato de que em países como Brasil e Argentina o comércio informal emprega boa parte da População em Idade Ativa, os dados etnográficos demonstram que há muito mais em jogo na construção de mercados informais do que uma definição contrahegemônica permite, num primeiro momento, entrever. Uma maneira de escapar a esse dualismo definitório está em atentar para a diversidade interna desses mercados, a saber, para a heterogeneidade de trajetórias, artefatos, entrepostos e técnicas de saber e fazer que são empregados na configuração de sujeitos, objetos e lugares - o que implica um olhar particularmente cuidadoso no acompanhamento de rotas de comércio e contextos de sociabilidade entre clientes e vendedores em seu cotidiano. 
Outro modo de tornar inteligível certo lugar de enunciação acerca da informalidade consiste em pensá-la enquanto uma arena de debates em aberto, suscetível de múltiplas definições e justificações (Boltanski e Thévenot, 2006). Este caminho nos conduz a uma antropologia das politicas de valor (Appadurai, 2008; Graeber, 2001), em que as frentes discursivas que emergem desses encontros configuram o próprio quadro de relações a que chamamos de "informal". Tal quadro teórico mais amplo tem o mérito de permitir um abandono parcial das definições prontas e acabadas do que sejam comerciantes informais, ou mercados não hegemônicos, a fim de dirigir o foco sobre as políticas econômicas de produção do valor. É preciso levar em consideração, ainda, que tais políticas que enquadram o "informal" enquanto o não hegemônico do "formal” são atravessadas por moralidades e práticas discursivas (Fassin, 2011; Fassin e Eideliman, 2012), elas próprias agências a buscar definições do estatuto que sujeitos, objetos e lugares, uns em relação aos outros, poderão ocupar nesse cenário.

Etnograficamente, isso implica em observar as configurações empíricas pelas quais são produzidas intersecções significativas entre sujeitos, objetos e lugares, uns em relação aos outros, na busca por um entendimento dos processos de valoração e produção da informalidade - numa dinâmica de objetificação ou, alternativamente, de materialização, através de cuja dialética humanos e não humanos, sujeitos e artefatos, são criados e adquirem agência e inteligibilidade através de formas, corpos, categorias, sonhos (Miller, 2005; Latour, 1993; 1999; Gell, 1998). Ao não abdicar das políticas concretas de valoração nas relações entre sujeitos e objetos - em que diferentes modalidades de agências se engajam em disputas pelo valor moral (Fassin e Eideliman, 2012) -, decorre que o problema da materialidade passa a ser, eminentemente, uma questão de poder; em outras palavras, pode-se decompô-lo em materialidades múltiplas pelas quais certos objetos, discursos, práticas ou sujeitos tornam-se mais tangíveis, objetificáveis e materializáveis que outros.

Para retornar à etnografia, sugiro que há diferentes equilíbrios semânticos entre sujeitos e objetos, que estão na base das políticas de valoração do que seja a “informalidade", tanto no caso das pretensões de formalização através da configuração de um shopping popular, em Porto Alegre, quanto no caso dos debates em torno da regulação de feiras de comércio como La Salada, em Buenos Aires.

No caso de Porto Alegre, fica claro que as políticas de formalização empreendidas pela empresa administradora, e ratificadas pelo poder público, implicavam um fino ajuste no equilíbrio de forças entre agentes de fiscalização e administração sobre assuntos 
estratégicos, tais como a distribuição e uso do espaço, bem como sobre o controle da qualidade e natureza dos bens colocados em circulação. A importância de cada comerciante passou assim a ser calculada em termos da assiduidade de seus pagamentos, da quantidade de bancas acopladas, compradas ou sublocadas, sua posição estratégica na arquitetura geopolítica do espaço e a natureza da mercadoria vendida, o que informava o grau de tolerância da administração sobre questões cruciais da regulação cotidiana das práticas comerciais tidas como legítimas.

A fiscalização, em associação com as políticas de socialização dos camelôs perpetradas pela empresa, passou a operar como um importante dispositivo de favorecimento ou exclusão, seja de determinadas modalidades de bens em comercialização - tidos como menos nocivos ao mercado de falsificações, ou que colocam em movimento um fluxo mais amplo de capital - ou de determinados sujeitos camelôs, alguns dos quais tidos como mais humanos que outros. Mais do que isso, uma imbricação de mútua valoração entre camelôs e mercadorias acabaria por se cristalizar a partir de critérios e estratégias de favorecimento, que sugerem uma associação entre lugar e sujeito; entre, respectivamente, o bloco $\mathrm{B}$ e os camelôs mais destituídos dos capitais simbólicos e econômicos necessários à sobrevivência como comerciantes bem-sucedidos no CPC. $\mathrm{O}$ argumento da transparência dos sorteios de pontos, ou das autuações de multa, ou ainda dos autos de fiscalização, é tanto mais eficiente quanto conseguir articular, discursivamente, ambas as instâncias, ao mostrar como certos sujeitos são nocivos em função das mercadorias que veiculam e das práticas que adotam para vendê-las.

Tais políticas de formalização, que tiveram por efeito produzir definições de "bons" sujeitos exclusivamente pelo que vendem e colocam em circulação, trouxeram consequências desiguais para os camelôs. Para o grupo da Praça XV, liderado por Alfonso, situado em sua maioria no bloco A, o camelódromo representou a infraestrutura necessária para que pudessem ampliar o negócio, sublocando, aumentando o dinheiro em circulação, a frequência das viagens ao Paraguai, Uruguai e, sobretudo, a São Paulo, estabelecendo novos nichos de mercadorias, adotando novas técnicas de vendas e posturas de apresentação de si, reinventando, enfim, a si mesmos como comerciantes.

Para o grupo de feirantes que ocupava os fundos do bloco B - e que constituía a maior parte de meus informantes -, o futuro que os espreita ainda é incerto. Na verdade, boa parte dos atuais comerciantes do bloco B já não são mais oriundos da rua, já que estes deixaram o camelódromo quer pela desistência voluntária, quer por meio de despejos litigiosos, quer porque venderam ou sublocaram o ponto. $\mathrm{Na}$ origem de seus problemas, 
não estava somente o fato de serem, desde o início, menos capitalizados. O que os levou a queixar-se contra a administração do empreendimento e a ausência do poder público como mediador desse processo tinha a ver, muito antes, com uma discordância e um desajuste em relação ao que imaginavam significava a nova figura do comerciante popular, e sua potencialidade de destruir o saber-fazer camelô. Na base dessa assimetria, estavam noções sobre os limites da concorrência, dos usos do dinheiro, da convertibilidade dos laços sociais em bens mercadológicos, da falsificação de mercadorias, e da desapropriação dos sentidos imaginados de tempo e espaço.

Em última instância, as mercadorias eram, aqui, representadas como coisas (Ingold, 2012), na medida em que não serviam apenas como medida econômica de valor de troca, nem os sujeitos se pensavam como simples intermediadores de objetos inanimados; ao contrário, eram pensadas como feixes de vida, pontes de comunicação entre vendedores e compradores, mundos que eram passíveis de conexão a partir do universo do camelô. Que o lastro dessa imaterialidade vivida no tempo e espaço da rua - objetivável na fidelização dos clientes, nas trocas jocosas, nas conversas com os habitués da rua -, se perdesse abruptamente na transição para a economia de mercado do camelódromo, eis o problema principal que se afigurava como ameaça simbólica a esses camelôs ${ }^{13}$.

No exemplo argentino, comparativamente, a dinâmica entre a configuração do mercado informal e de sua crítica assume a forma concreta das disputas entre Jorge Castillo e representantes de setores formais da economia, a partir de uma separação identitária entre sujeitos e artefatos mercantis. Em outras palavras, para o representante de La Salada, não há extensões semânticas entre os cuentapropistas da grande feira e os objetos que produzem como artefatos de consumo; não há, em última instância, uma passagem do objeto à coisa (Ingold, 2012), necessária para a percepção da extensividade existencial entre sujeitos e materiais. Isso porque, nessa perspectiva, não é a qualidade objetiva das mercadorias que fornecerá os parâmetros homológicos de definição de distinções significativas entre os sujeitos que a forjam. Não importa se são confecções, calçados, mídias copiadas, ou eletrônicos contrabandeados - ou ainda se esse comércio envolve a produção de artigos de marcas falsificadas.

Para Castillo, La Salada serve exclusivamente ao propósito de ganhar dinheiro e, por conseguinte, de "incluir" setores da população afetados por sucessivas crises econômicas no usufruto dos resultados palpáveis da economia nacional - isto é, permitindo que trabalhem (mesmo que sob o rótulo de informalizados e precarizados) em nome do direito elementar e difuso de "ganhar a vida", reivindicação que poucos críticos 
contestariam em si mesma. Nesse sentido, sua reputação econômica advém, justamente, de seu poder de capilarizar o alcance de La Salada, permitindo "democraticamente" que qualquer pessoa, por menos capitalizada que seja (isto é, desde que dispondo de recursos mínimos para alugar qualquer banca por uma ou duas horas durante uma feira), alcance um ponto de vendas e seja, literalmente, "incluída" no circuito da economia (in)formal. O mesmo se passa do lado do consumo, já que é a produção, nessas condições, que permitirá a prática de preços menores, autorizando o acesso de um público consumidor até então aviltado pelas sucessivas crises econômicas e com poder de compra reduzido.

Por outro lado, não deixa de ser curioso que, do lado da crítica, enquanto "feira informal", conquanto de amplas dimensões, a existência de La Salada tenha apenas recentemente surgido como "problema" diante de setores da economia formal. Propulsionada pela expansão das assim chamadas Saladitas, bem como pela iminência do tempo da política, fato é que tais eventos diacríticos colocaram La Salada no mapa moral e espacial das grandes discussões a respeito dos modelos de viabilidade econômicos e financeiros da nação, e o fizeram a partir de uma tentativa discursiva de conjunção entre sujeitos e mercadorias, na medida em que passaram a assinalar que os primeiros eram definíveis pelo caráter dos últimos. Assim, por exemplo, Benyakar sugeria que uma nação próspera demandava a imaginação de modelos econômicos baseados na formalização dos sujeitos - sua inclusão social através do pagamento de impostos e da visibilidade como “cidadãos de bem”.

A ironia de Castillo diante deste jogo de espelhos sobre como imaginar a economia e a política deixa entrever que é possível produzir outros pontos de enunciação, baseados na geração de renda e na sobreposição de circuitos formais e informais, lícitos e ilícitos, legais e ilegais. Sua reputação advém, em última instância, da habilidade com que maneja as fronteiras entre esses mundos nem sempre tão facilmente conciliáveis. Negociando alianças, apoios, inclusões e exclusões, Castillo deixa correr livre as negociações de pontos, preços e produtos, numa espécie de neoliberalismo periférico ao sistema hegemônico muito próximo, portanto, à postura de Alfonso, que trata da profissionalização da figura do camelô em termos de uma seleção dos mais e menos aptos à informalidade.

Enquanto isso, La Salada, como entreposto estratégico das políticas de produção do valor de sujeitos, objetos e lugares, segue irremediavelmente sua rítmica de inclusão pela (in)formalidade. Prova disso é a maneira ritualizada ou lúdica pela qual são encenados e dramatizados os debates em espaços públicos - o que deixa claro, de algum modo, que não há argumentos suficientemente sólidos para contestar sua existência, já que ela tende a ser 
um problema apenas para a reprodução da economia formal, dependente da arrecadação de tributos e das patentes de grandes marcas transnacionais. Por outro lado, há uma ampla gama de agentes que se beneficiam de sua existência - inclusive e, talvez até, sobretudo, a economia e a política formais; a primeira, porque a tributação nunca está completamente ausente, e a segunda porque, mal ou bem, a simples existência de La Salada permite sustentar o discurso de que há alternativas à crise viáveis ou em marcha, por meio da retórica da inclusão social de contingentes cada vez maiores de trabalhadores e pequenos empreendedores.

\section{Considerações Finais}

Até aqui, não há quaisquer registros de análises etnográficas ou sociológicas mais sistemáticas acerca do fenômeno La Salada, capazes de fazer frente à grandeza, diversidade e profusão de experiências que é capaz de suscitar. O que há são estudos jornalísticos e filmes documentários ${ }^{14}$ que, dado seu caráter especulativo e o tom quase denunciatório ou romântico de sua redação, interessam mais como partes constitutivas do fenômeno que tentam explicar do que, propriamente, fontes capazes de elucidá-lo. De modo semelhante, no caso brasileiro, apesar da profusão de estudos acerca de mercados de rua e as tensões envolvidas com a negociação de sua permanência nesses espaços com os poderes estabelecidos (sejam eles políticos ou econômicos), há relativamente poucas investigações acerca de processos efetivos de formalização através de remoções e reassentamentos sistemáticos para dispositivos capazes de tornar a informalidade visível, observável e, por assim dizer, gerenciável.

Da mesma forma, há uma carência compartilhada no que tange aos processos teóricos que envolvem definições mais precisas sobre o que seja o informal. Em geral, a literatura convencional sobre o tema costuma esbarrar em dois limbos conceituais distintos. De um lado, na ideia de que uma definição antropológica sobre o informal é intrinsecamente problemática, na medida em que as noções que a informam devem ser, por definição, emicamente construídas e, portanto, variáveis de contexto para contexto. Nessa perspectiva, deve-se observar as complexidades com que categorias como informal, ilícito e ilegal se entrecruzam e dão origem a distintos marcos regulatórios. De outro lado, no campo inverso, há quem defenda que uma definição possível da informalidade deva ser buscada na dimensão não hegemônica dos grandes mercados e corporações que estruturam 
a economia formal - isto é, no modo como são configurados os circuitos, redes e nós que estariam para além da regulação direta do Estado e do Mercado e se organizam a partir de outros instrumentos, como, por exemplo, a confiança e as relações pessoais (Beccaria, 2000; Ribeiro, 2006; 2010). No primeiro caso, corre-se o risco de encerrar prematuramente a discussão num particularismo histórico autocerrado; no segundo, o risco está em incorrer no seu oposto, isto é, de limitar demasiadamente a definição do estatuto ocupado pelo informal na relação com o formal, seja definindo-o como o apêndice deste último ou, alternativamente, em oposição a ele.

Sem negar a pertinência de cada uma dessas perspectivas, nesse artigo procurei argumentar por uma terceira via de entendimento da questão. Ao focalizar as políticas de construção do valor que estão na origem das disputas pelo caráter do que seja o informal, abriu-se espaço para uma terceira instância discursiva, situada a meio caminho entre o paroquialismo das definições etnográficas e o generalismo sociológico: as frentes discursivas produzidas por sujeitos estrategicamente situados em diferentes posições do espectro econômico. Mais do que definições prontas acerca do estatuto do informal, privilegiaram-se os processos de justificação e a dinâmica entre a construção desses mercados e suas críticas (Boltanski e Thévenot, 2006; Boltanski e Chiapello, 2009). Além disso, enfatizar a produção de valor enquanto processo de atribuição de sentidos políticos e imagens econômicas tem o mérito de direcionar-nos para a produção de relações morais entre sujeitos e objetos (Miller, 2005), a partir de cuja dialética resulta a construção do espaço como categoria simultaneamente etnográfica, moral e sociológica (Foucault, 1984).

Tal é o resultado final: que não se pode separar, sem incorrer em reducionismos teóricos, os discursos que produzem o valor das práticas que configuram o mercado; entre ambas há relações de coprodução mútua, na medida em que, por exemplo, não é possível diferenciar nitidamente as moralidades que compõem uma e outra instância significativa. Do mesmo modo, não há como definir, a priori, onde estão as fronteiras entre sujeitos e objetos - nem se tal fronteira é, de fato, pertinente -, apenas indicar por onde as disputas de sentido estão conduzindo a configuração empírica desses mercados enquanto lugares outros (Foucault, 1984) - isto é, enquanto beteropias embebidas em múltiplas camadas de significação, em feixes de relação que conduzem a outros lugares, imaginados ou reais, cuja complexidade não pode ser reconhecida ou definida de imediato.

Longe de excluir as vertentes hegemônicas - que pensam a informalidade a partir de definições êmicas particulares, ou então a enquadram como o outro lado homogêneo da economia formal -, a especificidade do argumento aqui discutido está em incluir a posição 
de enunciação das ciências sociais como mais uma narrativa nas disputas acerca dos sentidos políticos, econômicos e morais em jogo nesses arranjos definitórios. Essa passagem epistemológica não significa observar o Outro através do próprio espelho, mas reconhecer que o próprio universo da informalidade, entre tantos outros, constitui-se, acima de tudo, num contínuo universo em processo de tornar-se informal, em que tanto a ideia de sua existência quanto a definição do lastro dessa informalidade estão constantemente em negociação e redefinição.

\begin{abstract}
${ }^{1}$ Moisés Kopper é doutorando em Antropologia Social pelo Programa de Pós-Graduação da Ufrgs. É mestre em Antropologia Social e bacharel em Ciências Sociais pela mesma instituição. Atua nos seguintes temas: Antropologia Urbana, da Política, do Estado, da Economia; democracia participativa, culturas populares, mercados informais, classes médias, estratificação e mobilidade social. Principais publicações: "Etnografia de um Mercado em Transição". Teoria \& Sociedade, v. 19: 228-253, 2011; "Política, Economia e Mediação Simbólica". Cadernos de Campo, v. 20, 2012; "Tempos de Transição". Norus, v. 1: 95-119, 2013. E-mail: moiseskopper@gmail.com.
\end{abstract}

2 Não há consenso sobre o termo mais adequado para designar os comerciantes de rua. A noção de ambulante - ou camelô -, da qual o Estado habitualmente faz uso para a eles se referir, carrega uma conotação de expropriação, de alguém que não é senhor de sua terra e, por conseguinte, não é tido como cidadão. A noção de informal é, paradoxalmente, por demais ampla e restrita. É ampla porque, se pensada sob a ótica da formalidade - entenda-se legalidade -, acaba se dispersando num leque variado de atividades que no Brasil ocupa quase $50 \%$ da mão de obra ativa. Ao mesmo tempo, o conceito de informalidade é restritivo, pois focaliza apenas os aspectos jurídicos e tributáveis. Naturalizando os parâmetros legais, a noção de "informal" transforma as práticas do comércio de rua em meros desvios de conduta, empobrecendo, sobremaneira, os seus significados contextuais (Aguiar, 2007; Cunha, 2006; Machado da Silva, 2002; Mafra, 2005; Noronha, 2003; Pinheiro-Machado, 2004; 2009; Rabossi, 2004; Ribeiro, 2006; 2010). Ainda assim, esse artigo seguirá valendo-se dos termos "mercado informal" e "comerciantes de rua" para referir-se às interpenetrações e tensões entre sujeitos, objetos e dispositivos que pontuam a globalização não hegemônica.

3 Argumento, na dissertação de mestrado (Kopper, 2012), que a estes processos podemos nos referir, respectivamente, através das ideias de gentrificação (Leite, 2001; 2002) e de governamentalidade (Foucault, 1979). Muitos autores já discutiram os diferentes processos pelos quais os centros urbanos das grandes cidades vão, paulatinamente, passando por ciclos que alternam desocupação e degradação com reurbanização e patrimonialização. No caso específico com que me ocupo, a gentrificação de prédios e ruas históricas tinha o objetivo, mais do que de devolvê-las aos assim considerados "cidadãos de direito", ou de propiciar a eles um novo "ângulo" de contemplação desses patrimônios, promover uma nova instilação econômica, tratando de reconduzir a classe média - em permanente expansão - para esses espaços outrora ocupados.

4 Uma parte expressiva desses comerciantes não era residente na própria capital, mas nos municípios do entorno - consequência direta do adensamento do comércio informal nos anos 1980 -, o que tornava arriscado tentar justificar, aos porto-alegrenses, a destinação de seus tributos para o atendimento dessas demandas.

5 Disponível em: http://www.ferialasalada.com.ar/index.php/Historia/Seccion-General-de-la-Feria-LaSalada/Categoria-General-de-la-Feria-La-Salada/historia-de-la-feria-la-salada.html. Acessado em 17 de novembro de 2015.

${ }^{6}$ Entre as várias matérias de jornal analisadas, uma delas, publicada em junho de 2011, merece destaque. Com o sugestivo título de "Quizás usted tenga una 'Saladita' muy cerca de su casa y aún no lo sabe”, ela é 
paradigmática: "Un viento salado sopla sobre la escena comercial porteña. Lo que hace apenas un año era señalado como una tendencia menor hoy ya es visto como un aluvión con presencia en los principales barrios de la Ciudad de Buenos Aires. (...) El nivel de cómo esto está afectando a los comerciantes tradicionales se nota no sólo en las persianas que se bajan, sino también en la oferta de productos que se ofrecen en las vidrieras. Ahora antes de abrir un local primero averiguan si tienen una "saladita" cerca y, si esto es así, qué tipo de mercadería ofrece la feria para no competir de forma directa". Disponível em: http://www.iprofesional.com/notas/117728-Quizs-usted-tenga-una-Saladita-muy-cerca-de-su-casa-y-an-nolo-sabe. Acessado em 14.02.2014.

7 O Comitê Gestor é, essencialmente, um órgão que prevê a atuação tripartite dos principais atores envolvidos com a transição, na forma de reuniões mensais entre as partes. São elas: um representante indicado pela Secretaria Municipal de Indústria e Comércio; um representante indicado pela empresa Verdicon e, finalmente, um representante eleito pelos comerciantes populares.

8 Disponível em: https://www.youtube.com/watch?v=vpA8-o7VOqc. Debate realizado em 12 de outubro de 2011. Acessado em 16 de novembro de 2015.

9 Disponível em: https://www.youtube.com/watch?v=vpA8-o7VOqc. Debate realizado em 12 de outubro de 2011. Acessado em 16 de novembro de 2015.

10 Disponível em: http://www.24con.com/nota/32577-jorge-castillo-en-puerto-madero-me-discriminanporque-soy-de-la-salada/. Acessado em 16 de novembro de 2015.

11 Disponível em: https://www.youtube.com/watch?v=vpA8-o7VOqc. Debate realizado em 12 de outubro de 2011. Acessado em 16 de novembro de 2015.

12 Puerto Madero é, atualmente, um bairro nobre de Buenos Aires, e também um dos mais modernos da cidade. No fim do séc. XIX, serviu de porto, até ser ultrapassado pelo Puerto Novo e, em seguida ser abandonado. Com a recente revitalização, Puerto Madero tornou-se um centro financeiro e gastronômico da capital.

${ }^{13}$ Como discuto em outra oportunidade (Kopper, 2013), o cálculo em torno da natureza do que é passível de ser comercializado não passa, necessariamente, pela dimensão daquilo que poderia ser visto como mercadologicamente rentável. As bijuterias de Seu Zé, os chapéus de Dona Diva, e as confecções próprias de tantos outros camelôs, sugerem um trabalho imaterial de transubstanciação simbólica (Radomski, 2010), capaz de ser agregado ao valor de cada produto, na medida em que não são quaisquer bijuterias ou chapéus que estão em questão (mas aqueles capazes de produzir diferenças entre os próprios comerciantes que as vendem), de tal modo que a própria subjetividade camelô é agregada às propriedades objetivas daquela mercadoria que lhe conferem especificidade.

14 Além dos livros de Nacho Girón e de Sebastian Hacher, há também o documentário "Hacerme Feriante", de Julián D'Angiolillo (2011). Todas essas referências foram produzidas e publicadas em 2011, meses antes do pleito eleitoral nacional.

\title{
Referências bibliográficas
}

\author{
Aguiar, Julia Saldanha Vieira de
}

2007 Camelódromo da Praça Xv: improviso, comunicação e auto-organização. Porto Alegre, trabalho de conclusão de curso, Ufrgs, 131 pp. 
Appadurai, Arjun

2008 "Introdução: mercadorias e a política de valor". In (org.), A vida social das Coisas: as mercadorias sob uma perspectiva cultural. Niterói, Eduff, pp. 15-88.

BECCARIA, Luis

2000 "Argentina: informalidad laboral en el nuevo modelo econômico". In CARPIO, Jorge et al. (orgs.), Informalidady Exclusión Social. Buenos Aires, Siempro/OIT/Fondo de Cultura Económica, pp. 139-160.

2001 Empleo y integración social. Buenos Aires, Fondo de Cultura Económica.

BOLTANSKI, Luc e THÉVENOT, Laurent

2006 On Justification: Economies of Worth. Princeton, New Jersey, Princeton University Press.

Boltanski, Luc e Chiapello, Ève

2009 O Novo Espirito do Capitalismo. São Paulo, Martins Fontes.

CunHA, Manuela I. P. da

2006 "Formalidade e Informalidade: questões e perspectivas". Etnográfica, Lisboa, vol. X (2): 219-231.

D’ANGIOLILLO et al.

s/d Feria La Salada: una centralidad periférica intermitente en el Gran Buenos Aires. Buenos Aires, manuscrito.

D'ANGIOLILLO

2011 Hacerme Feriante. Filme Documentário, Buenos Aires, 94min.

De Certeau, Michel

1994 A Invenção do Cotidiano: artes de fazer. Petrópolis, Vozes.

FASSIN, Didier

2011 "Towards a Critical Moral Anthropology: a European Research Council Programme". La Lettre, n. 49.

FASSIN, Didier e EIDELIMAN, Jean-Sébastien

2012 Les Économies morales contemporaines. Paris, La Découverte.

FOUCAULT, Michel

1984 "Des espaces autres. Hétérotopies. (conférence au Cercle d'études architecturales, 14 mars 1967)". Architecture, Mouvement, Continuité, Paris, n. 5: 46-49. 1979 “A Governamentalidade". In Microfísica do Poder, Rio de Janeiro, Graal, pp. 277-293. 
GELL, Alfred

1998 Art and Agency: an anthropological theory. Oxford, Oxford University Press.

GIRÓN, Nacho

2011 La Salada: radiografía de la feria más polémica de Latinoamérica. Buenos Aires, Ediciones B.

GRAEBER, David

2001 Toward an Anthropological Theory of Value: the False Coin of Our Own Dreams. New York, Palgrave.

HANNERZ, Ulf

2011 Culture, Globalization and the World-System: Contemporary Conditions for the Representation of Identity. Minneapolis, University of Minnesota Press.

HACHER, Sebastian

2011 Sangre Salada: una feria en los márgenes. Buenos Aires, Marea.

INGOLD, Tim

2012 “Trazendo as Coisas de Volta à Vida: emaranhados criativos num mundo de materiais". Horizontes Antropológicos, Porto Alegre, vol. 18, n. 37: 25-44.

KOPPER, Moisés

2012 De camelôs a lojistas: etnografia da transição do mercado de rua para um shopping popular em Porto Alegre-rs. Porto Alegre, dissertação, Ufrgs, 196pp.

2011 "Política, Economia e Mediação Simbólica: Notas etnográficas sobre a constituição da chefia social a partir da experiência do Camelódromo de Porto Alegre". Cadernos de Campo, São Paulo, v. 20: 33-50.

2013 "Tempos de Transição: a reconfiguração dos mercados de rua e a implementação de um shopping popular em Porto Alegre/Rs". Norus, Pelotas, vol. 01, n. 01: 95-119.

LATOUR, Bruno

1993 We Have Never Been Modern. Hemel Hempstead, Harvester Wheatsheaf.

1999 Pandora's Hope: An essay on the Reality of Science Studies. Cambridge, Harvard University Press.

LEITE, Rogerio Proença

2002 "Contra-Usos e Espaço Público: notas sobre a construção social dos lugares na Manguetown". Revista Brasileira de Ciências Sociais, São Paulo, vol. 17, n. 49: 115-134. 
2001 Espaço público e política dos lugares: usos do patrimônio cultural na reinvenção contemporânea do Recife Antigo. Campinas, tese, Unicamp.

Machado da Silva, Luís Antonio

2002 "Da informalidade à empregabilidade". Caderno CRH, Salvador, n. 37: 81-109.

MAFra, Patrícia Delgado

2005 A "pista" e o "camelódromo": camelôs no Centro do Rio de Janeiro. Rio de Janeiro, dissertação, UFRJ.

MiLLER, Daniel

2005 "Materiality: An Introduction". In (ed.), Materiality. Durham, Londres, Duke University Press.

NorONHA, Eduardo G.

2003 “"Informal', Ilegal, Injusto: percepções do mercado de trabalho no Brasil”. Revista Brasileira de Ciências Sociais, São Paulo, vol. 18, n. 53: 111-129.

Palmeira, Moacir e Herédia, Beatriz

1995 "Os comícios e a política de facções”. Anuário Antropológico, Brasília, v. 94: $31-94$.

PINHEIRO-MACHAdO, Rosana

2004 "A Garantia soy yo": etnografia das práticas comerciais entre camelôs e sacoleiros na cidade de Porto Alegre e na fronteira Brasil/Paraguai. Porto Alegre, dissertação, Ufrgs.

2009 Made in China: Produção e circulação de mercadorias no circuito China-Paraguai-Brasil. Porto Alegre, tese, Ufrgs.

RABOSSI, Fernando

2004 Nas ruas de Ciudad del Este. Rio de Janeiro, tese, Museu Nacional/UfrJ.

RADOMSKI, Guilherme W.

2010 "A dádiva da rede: processos de transubstanciação simbólica”. In

Certificação participativa e regimes de propriedade intelectual. Porto Alegre, tese, Ufrgs, pp. 128-159.

RiBEIRO, Gustavo Lins

2010 “A Globalização Popular e o Sistema Mundial Não-Hegemônico”. Revista Brasileira de Ciências Sociais, São Paulo, vol. 25, n. 74: 21-38.

2006 "Economic Globalization from below". Etnográfica, Lisboa, vol. x (2): 233-249. 
MOISÉS KOPPER. DOS MERCADOS INFORMAIS ÀS POLÍTICAS NÃO HEGEMÔNICAS DE VALOR...

SOlANO, Eduardo Chávez

2004 Prácticas Sociales en el Trabajo Informal: los feriantes de San Francisco Solano. Buenos Aires, tese, Flacso.

WALLERSTEIN, Immanuel

1974 The modern World-System. Nova York; Londres, Academic Press.

WOLF, Eric

1982 Europe and the People without History. Berkeley, University of California Press. 


\title{
From Informal Markets to non-hegemonic Politics of Value: Crosscutting approaches between Porto Alegre and Buenos Aires in the production of street objects and subjects
}

\begin{abstract}
The anthropology of informal markets always faced with some difficulty the basic problem of proposing definitions of what constitutes the informal. Economists and sociologists have proposed all too generalizing conceptualizations, linking it to the formal economy; anthropologists run into excessively particularized conceptions, often denying the heuristic ability of the notion. This paper suggests a third answer to the problem. It explores the economic policies that attach value to subjects, objects and locations, framing and producing them in relation to each other. It focuses on how competing discourses on informality - imagined, mobile and incomplete - take form and are performed. Ethnographically, the article draws from the transition of a street market to a popular mall in Porto Alegre/RS; and on the public debates between journalists, businessmen and traders about the expansion of the world's biggest informal marketplace, called "La Salada", in Buenos Aires.
\end{abstract}

KEYWORDS: Informality, Formalization, Value, Ethnography, Camelódromo, La Salada

Recebido em fevereiro de 2014. Aceito em dezembro de 2014. 